ISSN: $1980-055 X$

\title{
DINÂMICA ATMOSFÉRICA E ANÁLISE GEOESTATÍSTICA DO CLIMA DA ÁREA DE INTEGRAÇÃO PAISAGÍSTICA "RAIA DIVISÓRIA" SP/PR/MS: UMA PROPOSTA DE TIPOLOGIA CLIMÁTICA ${ }^{1}$
}

\author{
Carlos Batista da Silva², João Lima Sant'Anna Neto ${ }^{3}$ José Tadeu Garcia \\ Tommaselli ${ }^{4}$ e Messias Modesto dos Passos ${ }^{5}$
}

\begin{abstract}
RESUMO
Este artigo tem por objetivo propor um modelo de classificação climática para a região média do Rio Paraná, sustentado por técnicas e conceitos consagrados na climatologia, como é o caso da Análise de Cluster (JOHNSTON, 1968) e do Ritmo Climático (SORRE, 1951 \& MONTEIRO, 1969). Para tanto, utilizou-se mais de 20 variáveis climáticas e expressões espaciais coletadas junto a mais de 40 unidades de observação meteorológicas localizadas na área de pesquisa. Essas variáveis climáticas e expressões espaciais mensuráveis foram tratadas por técnicas estatísticas tais como: os cálculos das médias mensais, sazonais e anuais, cálculo de desvio padrão, médio, cálculo de tendências e de regressão linear simples e o cálculo de correlação de Pearson. Após o tratamento estatístico dos dados climatológicos foi estabelecido um modelo de classificação climática por meio das análises de agrupamento e, posteriormente, um modelo de distribuição percentual dos sistemas atmosféricos sobre a área de estudo. No final do trabalho, realizou-se a fusão entre os resultados obtidos com modelo climático da análise de agrupamento e o modelo de participação dos sistemas atmosféricos, culminando na proposta final de modelo de classificação climática, pautada tanto na análise quantitativa como na análise genética.
\end{abstract}

Palavras-chaves: Classificação Climática, Ritmo Climático, Cluster Analysis, Raia Divisória

\section{ATMOSPHERIC DYNAMICS AND GEOSTASTICAL ANALYSIS OF THE CLIMATE AT LANDSCAPE INTEGRATION AREA NAMED "FRONTIER PARTING" SP/PR/MS, BRAZIL: A CLIMATE TIPOLOGY PROPOSAL TIPOLOGY.}

\footnotetext{
${ }^{1}$ Projeto temático financiado pela Fapesp.

${ }^{2}$ Aluno bolsista do CNPq/PIBIC e bacharelando do curso de Geografia da FCT/UNESP, campus de Presidente Prudente, São Paulo, Brasil. E-mail:. krlosbatist@gmail.com.

3 Professor Adjunto do Departamento de Geografia da FCT/UNESP, campus de Presidente Prudente, São Paulo, Brasil. E-mail:. joaolima@fct.unesp.br. (orientador)

4 Professor Doutor do Departamento de Geografia da FCT/UNESP, campus de Presidente Prudente, São Paulo, Brasil. E-mail:. tadeu@fct.unesp.br. (co-orientador)

5 Professor Adjunto do Departamento de Geografia da Universidade Estadual de Maringá, Maringá, Paraná, Brasil
} 


\begin{abstract}
The aim of this article is to propose a model to climate classification for the medium region of the Parana River, supported by classical techniques and concepts of the climatology, such as cluster analysis (JOHNSTON, 1968) and the climatic rhythm (SORRE, 1951; MONTEIRO, 1969). Hence, it was used more than 20 climatic variables, collected by more than 40 stations of spatial meteorological observation located in the research area. These measured climatic variables were treated by statistical techniques such as annual, seasonal and monthly averages, standard deviations, trends, linear regressions and Pearson correlation coefficients. After the statistical treatment of the climatic data, it was established a model of climatic classification by means of cluster analysis, and so, a model of percent distribution of the atmospheric systems all over the whole area under study. At the end, it was performed the fusion among the results get from the climatic model of the cluster analysis and the model of atmospheric systems participation, with the final propose of a climate classification model as a climax, based upon both quantitative and genetic analysis.
\end{abstract}

Key-words: Climatic Classification, Climatic Rhythm, Cluster Analysis, Frontier Parting.

\title{
Introdução
}

Classificar os diferentes climas da Terra sempre foi uma das necessidades dos diversos grupos sociais, na perspectiva do conhecimento e domínio do mundo natural.

Desde a época de Ptolomeu (200 d.C), Parmênides (530 - 460 a.C) e Eudoxio (408-355 a.C.), já havia esboços de tentativas de divisão climática em zonas, fundamentadas "nas considerações astronômicas que regulam a duração dos dias e das noites" (MORIZE, 1927, p.4).

Todo o legado deixado pelos gregos ao estabelecerem propostas preliminares de classificações climáticas tinha como cerne a astronomia, considerada um referencial de controle, pelo menos para a hierarquização dos fenômenos meteorológicos a comporem o sistema classificatório, segundo as afirmações de Toledo (1973, p.03).

As tentativas iniciais de classificar os climas da Terra quase sempre convergiam a um mesmo ponto, o de dividir a Terra em cinco zonas climáticas, sendo elas: uma zona tórrida (equador térmico do planeta), duas regiões frígidas (círculos polares) e uma zona inserida entre as tórridas e frígidas, conhecida como temperada (MORIZE, 1927, p.05).

Com o desenvolvimento técnico e com o aperfeiçoamento da instrumentação, como o barômetro de Torricelli, os termômetros e os pluviômetros, tornou-se possível obter informações fundamentais de alguns dos principais elementos climáticos. Para Toledo (1973, p. 02), o desenvolvimento da instrumentação técnica acabou gerando uma atomização da visão de conjunto que se tinha na época dos gregos a respeito do clima. 
As típicas classificações difusas, formuladas a partir das informações meteorológicas fragmentadas feitas por navegadores, exploradores, observadores eventuais entre outros, foram essenciais para as primeiras classificações climáticas dos tempos modernos, realizadas por De Candolle (1874) e Supran (1896), destacado tanto por Morize (1927) quanto por Toledo (1973).

Austin Miller (1931) evidenciou que Supran (1896) sugeriu em seu Atlas of Meteorology de Bartholomew uma divisão do mundo em 35 localidades, caracterizadas cada uma por combinações dos elementos climáticos. A classificação feita por Supran (1896) não se trata de um modelo classificatório do clima e sim uma grande enumeração das variáveis climatológicas.

Já De Candolle (1874), apud Koeppen (1923), dividiu o planeta em cinco grandes zonas climáticas, sendo ela Megatermas, Xerofilas, Mesotermas, Microtermas e Hequistermas. Entretanto, esse modelo de classificação baseou-se muito mais num modelo de taxionomia de plantas, sustentado pela quantidade de calor e de umidade vitais ao desenvolvimento fenológico dos vegetais, do que um exemplo de classificação dos climas.

Os modelos de classificação de De Candolle e Supran influenciaram inúmeros personagens da climatologia mundial, como Jullius Hann (1903), WiIhelm Koeppen (1923), Austhin Miller (1931) e tantos outros. Esses adotaram a metodologia de classificação numérica de superposição das normais climatológicas e passaram a incorporar em seus modelos tanto as variáveis climáticas quantitativas quanto os sistemas espaciais fitográficos, propostos por De Candolle (1874) e Supran (1896). Desta forma, boa parte das análises realizadas era marcada por um caráter estático, ou seja, por uma atmosfera não dinâmica e não pulsante e facilmente mensurável por médias aritméticas, que aos "olhos" da teoria das massas de ar e frentes de Bjerkness (1921), seria um dos pilares da Escola Tradicional de Meteorologia, que necessitavam serem revistos. Entretanto, deve-se destacar que todas as contribuições às ciências atmosféricas feitas pela Escola Tradicional foram importantes para sua época e que seria mais que normal, para o progresso da ciência, a superação de muitos dos postulados por si estabelecidos.

Com a teoria da frente polar de Bjerkness (1921) e com as contribuições de Rossby (1938), Bergeron (1939), entre outros membros da escola norueguesa de meteorologia, todos os modelos de circulação geral da atmosfera realizada pela escola tradicional foram redefinidos pelas escolas de Bergeron e de Chicago que passaram a considerar os quadros de atuações dos sistemas atmosféricos, diferenciados sobre a superfície terrestre, como primordiais para o desenvolvimento do novo paradigma: o da dinâmica da atmosfera.

A partir do legado deixado pelas escolas Norueguesa e de Chicago, muitos foram os trabalhos de climatologia que passaram a não mais considerar os elementos climáticos mensuráveis como as únicas variáveis de análise do sistema climático, como se fazia na época de Hann, Koeppen, De Candolle e Supran, passando, agora, a incorporar (neste mesmo sistema), a dinâmica atmosférica dos locais.

O conhecimento da circulação geral e regional e da dinâmica da atmosfera possibilitou para inúmeros pesquisadores do mundo, como Alissov (1936), Khromov (1954), Strahler (1951), Meynier (1956), Pédélaborde (1956), Flohn (1968), Critchfield (1964) e Blutgens (1966) apud (TOLEDO, 1973, p.08), 
a formularem esboços climáticos do planeta levando em consideração os aspectos dinâmicos da atmosfera e os legados da escola escandinava de meteorologia.

No Brasil, as influências de Bjerkness, Rossby e Bergeron foram essenciais para a elaboração da obra clássica dos engenheiros Adalberto Serra e Leandro Ratisbonna de 1942. O estudo destes dois autores, tanto serviu como referencial de um quadro climático continental da América do Sul quanto subsidiou uma série de estudos em climatologia geográfica como os desenvolvidos por Monteiro (1962, 1969 e 1973), Tarifa (1975), Conti (1975) e Sant'Anna Neto (2001).

Com o legado da escola norueguesa de meteorologia, com as contribuições da obra de Serra e Ratisbonna (1942), e, sobretudo, diante das influências sorreanas, Monteiro (1962) insere na análise geográfica do clima a preocupação com a gênese dos tipos de tempo e propõe uma metodologia de classificação climática de caráter genético, a partir de análises qualitativas dos elementos meteorológicos.

A contribuição de Monteiro (1962) à classificação climática foi primordial para o desenvolvimento de trabalhos clássicos e essenciais ao desenvolvimento da climatologia geográfica do Brasil, como os desenvolvidos por Auoad (1982), Zavatini (1990) e Sant'Anna Neto (1990).

\section{A área de estudo}

A área de estudo, denominada como Raia Divisória, situa-se entre as coordenadas: $19^{\circ} 57^{\prime}$ e $24^{\circ} 38^{\prime}$ de latitude Sul e 50 $0^{\circ} 3^{\prime}$ e $54^{\circ} 18^{\prime}$ de longitude Oeste e se encontra inserida nos Estados de São Paulo, Mato Grosso do Sul e Paraná, como destaca a figura 1.

A gênese do termo Raias Divisórias tem a sua origem nos países Ibéricos e pode ser compreendido como sendo:

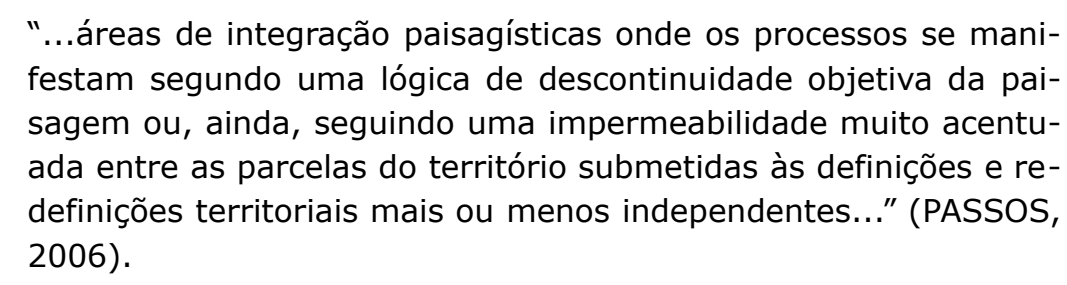

Trata-se de uma extensa planície do curso médio do Rio Paraná, formada por Latossolo Vermelho em boa parte do Estado do Mato Grosso do Sul, noroeste do Paraná e no Pontal do Paranapanema em São Paulo. Além disso, observa-se nas várzeas dos rios Iguatemi e Amambaí (ambos em Mato Grosso do Sul), a presença de Planossolo Hidromórfico e algumas manchas de Argissolo no extremo oeste Paulista, segundo a classificação do IBGE (2005).

A região apresenta cerca de $40.000 \mathrm{Km}^{2}$, e é formada por mais de 60 municípios, destacando-se pela sua importância regional Presidente Prudente em São Paulo, Maringá, Londrina, Apucarana, Umuarama e Paranavaí no Paraná e Naviraí, Ivinhema e Ribas do Rio Pardo no Mato Grosso do Sul. 


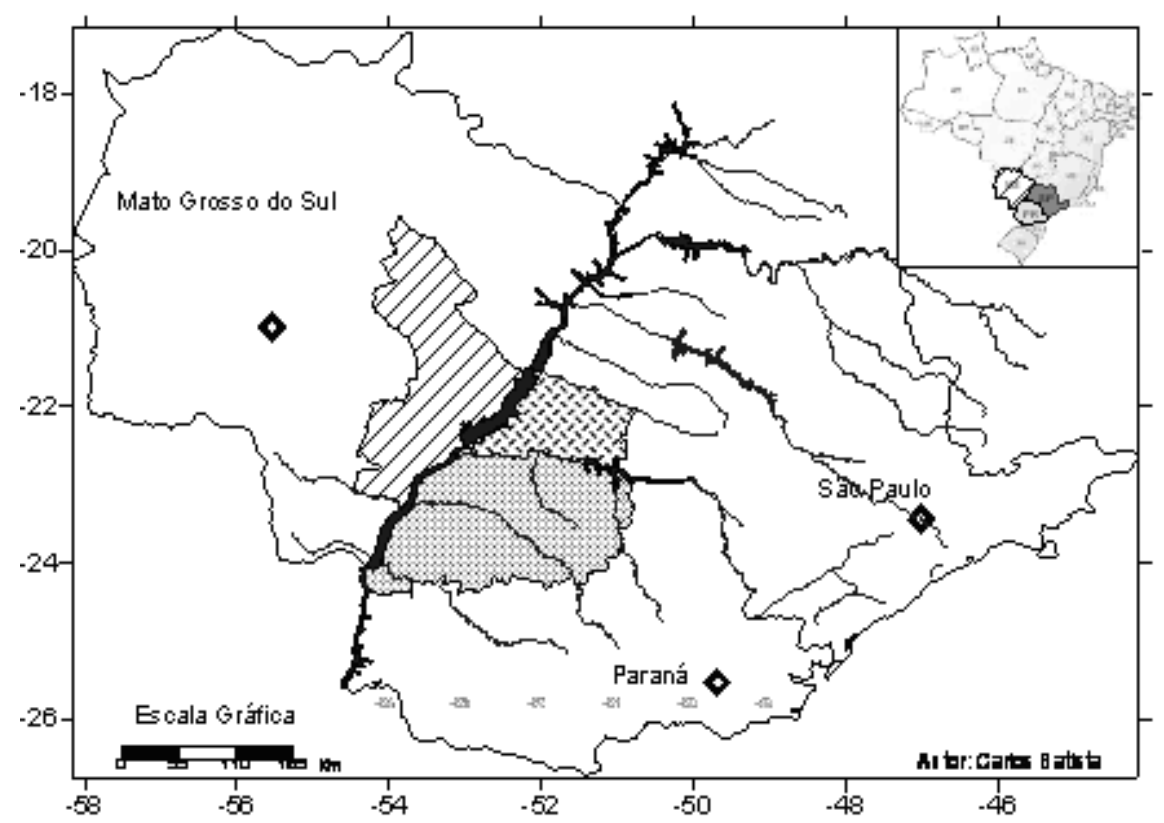

Figura 1. Área da Raia Divisória São Paulo, Mato Grosso do Sul e Paraná

A maior parte de seu território apresenta uso destinado à pecuária extensiva e propriedades agrícolas, em que predominam as culturas de cana-deaçúcar, milho e soja.

\section{Classificações climáticas e algumas influências teórico- metodológicas}

Classificar o clima de uma determinada região consiste num trabalho muito dispendioso por necessitar de inúmeras análises das principais variáveis climáticas, além do emprego de técnicas estatísticas coerentes à proposta a ser alcançada. Mas apenas o uso de dados meteorológicos e técnicas estatísticas, não são suficientes para que sejam desvendadas as configurações climáticas de uma determinada porção territorial, pois como afirma Johnston (1968), há uma certa subjetividade na avaliação objetiva da ação de classificar.

Os estudos que propõem tipologias e classificações climáticas devem fazer considerações sobre os principais fatores do clima (altitude, latitude e longitude), assim como o emprego de métodos teóricos e conceitos aplicáveis que visam compreender a fundo os processos genéticos e dinâmicos da atmosfera, como faz o paradigma do ritmo climático desenvolvido por Sorre (1951) e preconizado na escola geográfica brasileira por Monteiro (1969 e 1971). Além disto, em função da escala de abordagem, os fatores geográficos assumem maiores ou menores proporções determinadas pela configuração da paisagem regional. 
No Brasil, muitos foram os trabalhos que aceitaram o desafio de propor estudos de tipologia e de classificação climática, como os desenvolvidos por Monteiro (1951, 1962 e 1973), Auoad (1982), Zavatini (1990), Sant'Anna Neto (1990 e 1995), Boin (2000), Tarifa et al (2006), além de outras obras citadas por Zavatini (2000) em seu inventário, como os de Pitton (1985) e Orselli (1989).

Boa parte destes trabalhos teve como base de sustentação teórica, o paradigma do ritmo climático, essencial para se compreender a fundo os processos genéticos da atmosfera, assim como a distinção dos tipos climáticos em cada porção territorial em análise.

Além do emprego do paradigma do ritmo, alguns destes estudos contaram com o auxílio de técnicas estatísticas consagradas e bem refinadas, como é o caso das análises fatorial e de agrupamento, utilizadas, exclusivamente, por Auoad (1982) ao fazer uma proposta de classificação climática para o Estado da Bahia.

As técnicas estatísticas empregadas por Auoad (1982) são as mesmas que contribuíram nos estudos de classificação climática desenvolvidos por Ayoade (1977) ao propor um modelo de classificação climática para a Nigéria, por Mc Boyle (1973) ao tentar estabelecer tipologia climática para a Austrália e por Abler et. al (1971) ao estabelecer critérios para um modelo de classificação climática para o território dos Estados Unidos.

Esses três estudos mencionados se preocuparam, apenas, com os atributos climáticos quantitativos, visando uma proposta de análise espacial, sem preocupações com as manifestações temporais do clima e seu ritmo.

Para Auoad (1982), todos os estudos de classificação climática que se utilizaram apenas das análises fatorial e de agrupamento limitam-se a oferecer "modelos espaciais", ainda que revelem estruturação climática. Auoad (1982) destaca que para um sistema climático (ou um modelo de classificação) ser bem compreendido é preciso uma análise temporal que vincule a sucessão de eventos atmosféricos ligados uns ao outros.

Desta forma, Auoad (1982) evidencia a importância do paradigma do ritmo para os estudos que visam propor tentativas de classificação climática à determinada porção territorial.

Por fim, o objetivo desta pesquisa é propor uma tipologia climática para a área da Raia Divisória por meio de análises genéticas e quantitativas.

\section{Materiais e técnicas}

Para a realização desta pesquisa, foram utilizados 44 pontos de coleta de dados climatológicos, entre postos pluviométricos e estações meteorológicas. Após a seleção desses pontos de coletas foram selecionadas 5 variáveis climáticas e 20 expressões temporais (mensais, sazonais e anuais) destacadas na tabela 1

As fontes destes dados foram: o IAC (Instituto Agronômico de Campinas), ANA (Agência Nacional de Águas), DAEE (Departamento de Águas e Ener- 
gia Elétrica), INMET (Instituto Nacional de Meteorologia), IAPAR (Instituto Agronômico do Paraná) e a UHE de Itaipu. O segmento temporal compreendido destes dados se estende de 1960-2005.

Tabela 1. Relação das variáveis climatológicas e de suas expressões temporais

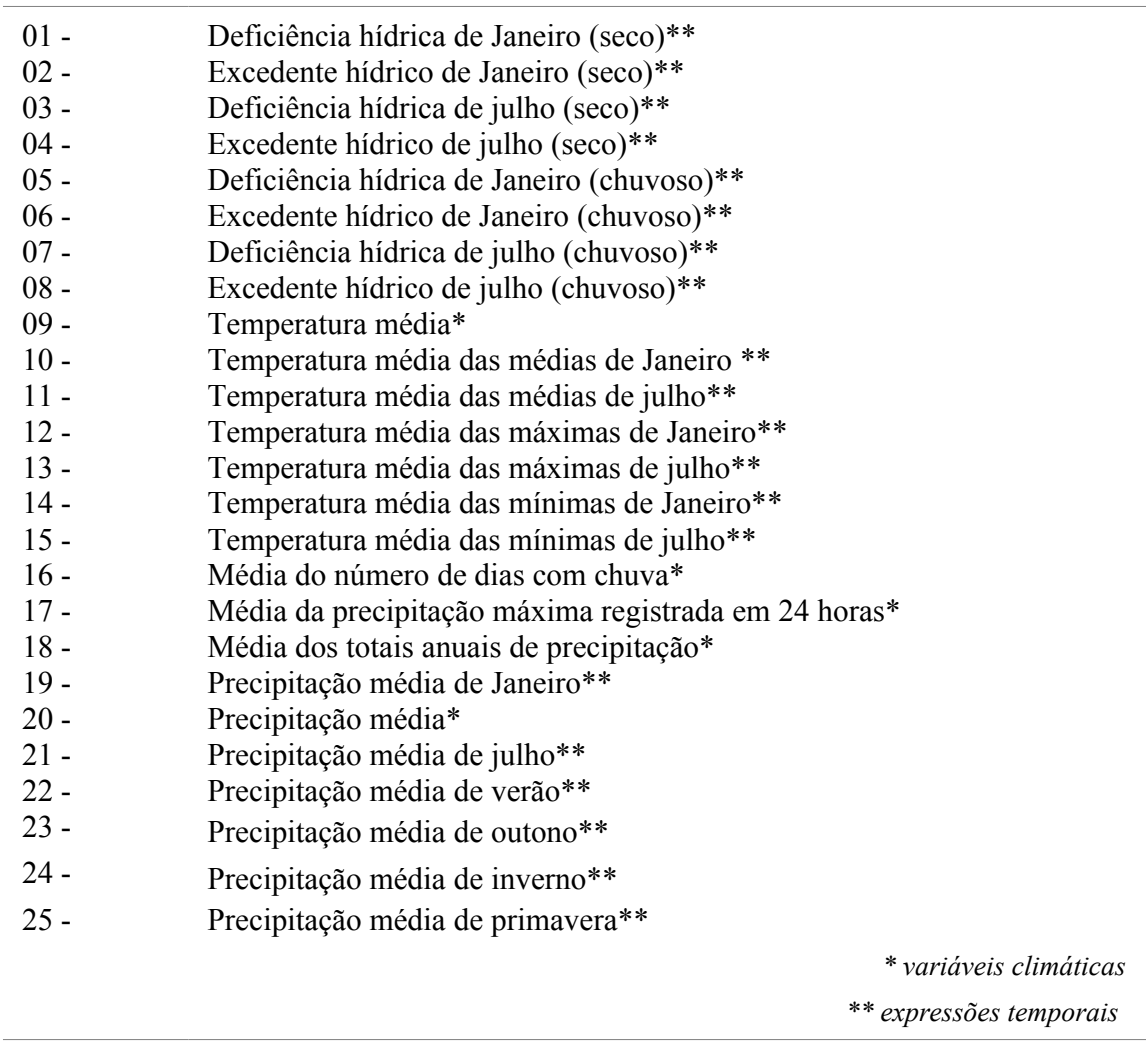

Todos os dados utilizados foram tratados estatisticamente utilizando técnicas clássicas da estatística como os cálculos das médias mensais, sazonais e anuais, cálculo de desvio padrão, médio, cálculo de tendências e de regressão linear simples e cálculo de correlação de Pearson.

Já as técnicas e os métodos empregados para a realização das análises de caráter mais qualitativa foram: a técnica de análise de agrupamentos (JOHNSTON, 1968), a técnica da análise rítmica (MONTEIRO, 1971) e a técnica do método sintético das massas de ar (PÉDÉLEBORDE, 1959).

\section{Roteiro metodológico estabelecido}

Na perspectiva de se obter um modelo inicial de classificação climática (de ordem mais quantitativa do que qualitativa) para a área da Raia Divisória, 
foram estabelecidos como critérios de análise os cálculos de correlação, inicialmente, entre as 5 variáveis climatológicas e as 20 expressões temporais descritas na tabela 1 e, posteriormente, entre as 44 unidades espaciais de observação meteorológicas.

Como resultado desta análise, obteve-se duas pirâmides/matrizes de dados, sendo que a primeira (correlações entre variáveis climáticas) evidenciou o grau de confiabilidade existente entre as variáveis e as expressões temporais e a segunda (correlação entre todas as unidades de observação meteorológica) foi fundamental para representar as semelhanças da marcha das variáveis climáticas mensuráveis de cada unidade de observação meteorológica espacial. Ou seja, essa segunda correlação resultou numa matriz de dados - em função de cada localidade - para serem submetida à análise de agrupamentos e subsidiar a identificação dos grupos das unidades espaciais que apresentam características semelhantes em suas variáveis climáticas e em suas expressões temporais.

A análise de agrupamento foi utilizada como estratégia de definição das unidades de observação espacial que resultaram em 6 grandes grupos climáticos que sustentaram a base inicial para a identificação das diferentes tipos climáticos observados na área da Raia Divisória. A obtenção desses 6 grupos foi estabelecida pelo corte ${ }^{6}$ de similaridade de 0,32 como mostra o da figura 2.

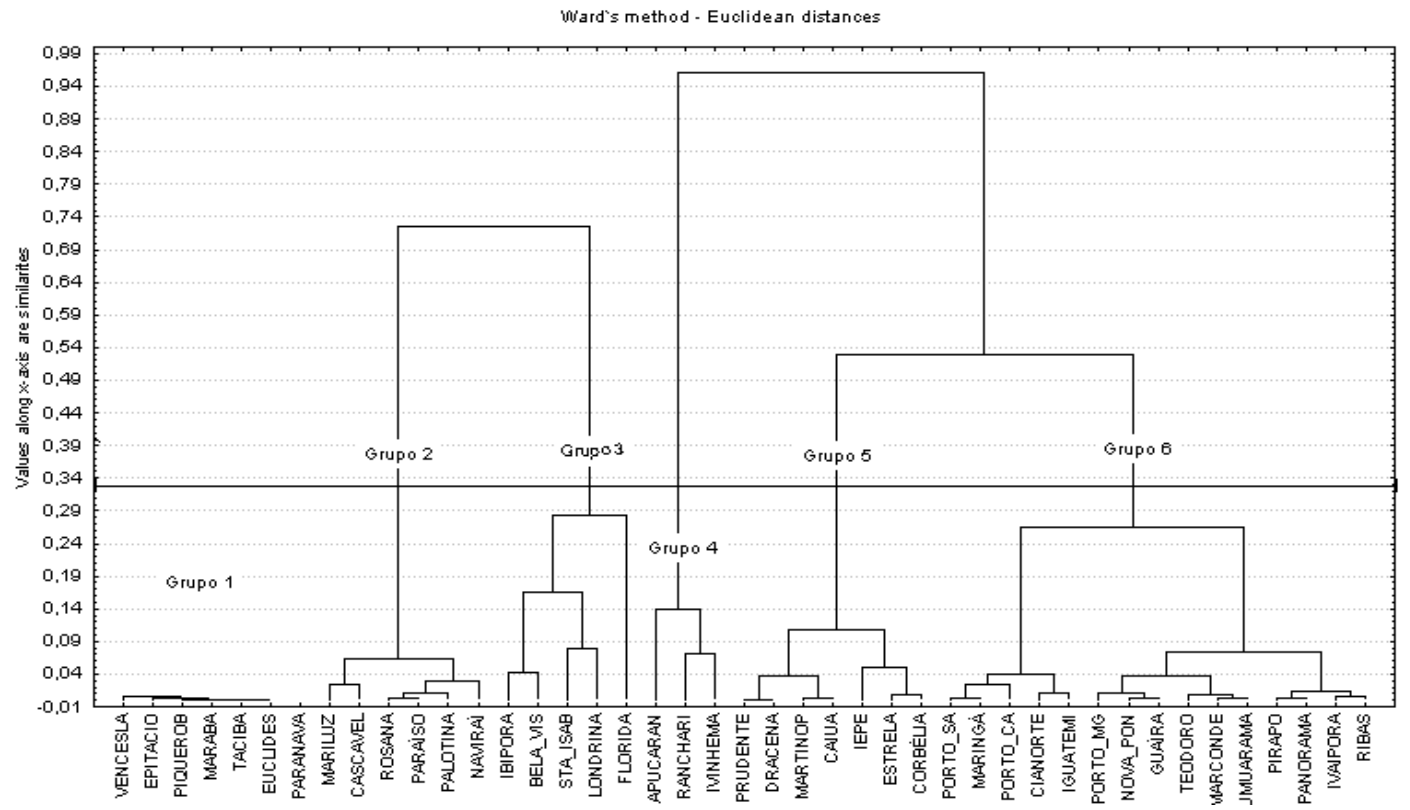

Figura 2. Dendograma de correlação entre as unidades espaciais de observação meteorológicas na Área da "Raia Divisória" SP/MS/PR

A partir da obtenção desses 6 grupos climáticos, utilizou-se o método de representação cartográfica "nearest neighbor" (vizinho mais próximo) presen-

\footnotetext{
${ }^{6}$ Os graus de similaridade estão distribuídos aleatoriamente e é o corte (estabelecido por quem executa o estudo) que determina a formação dos grupos (AUAD, 1982).
} 
te no software Surfer ${ }^{6} 8.0$ para efetuar a espacialização das unidades de observação e das tipologias climáticas obtidas com a análise de agrupamento que serão melhores discutidas nos resultados da pesquisa.

Após a identificação dos 6 grupos climáticos, utilizou-se da técnica da análise rítmica (MONTEIRO, 1971) e dos preceitos do conceito de ritmo (SORRE, 1951; MONTEIRO, 1969) para se obter um melhor conhecimento da dinâmica atmosférica sobre a área de pesquisa.

A utilização da técnica dos anos-padrão revelou que o ano de 1996 apresentou características próximas do habitual (situação normal) para a maioria das unidades de observação meteorológica. Para identificar a freqüência da participação dos tipos de tempo atuantes sobre a área de pesquisa, adotou-se o método sintético das massas de ar de Pédélaborde (1959).

Para facilitar a representação dos sistemas atmosféricos atuantes durante o ano de 1996, sobre o espaço geográfico da Raia Divisória, adotou-se o critério de análise por "eixos transversais" das seguintes unidades de observação espaciais: Ivinhema na porção-sul-mato-grossense, Presidente Prudente em São Paulo e Palotina, Londrina e Cianorte no Estado do Paraná, como mostra a figura 3.

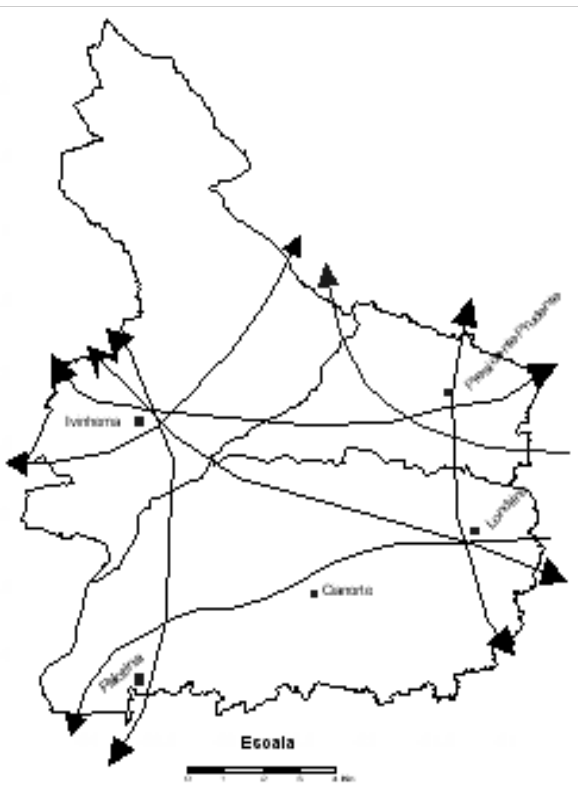

Figura 3. Representação dos eixos transversais utilizados para a identificação dos sistemas atmosféricos atuantes em anos habituais

Com a utilização da técnica de análise por eixos transversais foi possível observar o índice percentual de participação dos sistemas atmosféricos sobre a área da Raia Divisória, contribuindo, assim, para o melhor entendimento de sua dinâmica, assim como a freqüência e o predomínio dos tipos de tempo sobre cada porção da área de estudo.

$\mathrm{Na}$ tentativa de sintetizar a participação dos sistemas atmosféricos observados sobre a Raia Divisória (para o ano habitual de 1996), elaborou-se uma base cartográfica para observar os índices de participação dos tipos de tempo sobre a área de pesquisa, que será melhor discutida mais adiante.

Esta segunda parte da pesquisa buscou estabelecer critérios muito mais qualitativos - a partir da identificação dos sistemas atmosféricos e da verificação do ritmo climático sobre

a região do que quantitativos.

7 Esta é uma técnica muito viável e utilizada em estudos que visam conhecer o índice participativo dos sistemas atmosféricos de localidades diferentes em momentos semelhantes. É uma técnica muito usada nos trabalhos de climatologia que objetivam a classificação climática em escalas regionais, como os desenvolvidos por Auoad (1982) e Zavatini (1990), além de auxiliar em trabalhos de clima urbano, como os realizados por Amorim (2005). 
Para finalizar, buscou-se estabelecer correlações entre os resultados obtidos com a análise de caráter mais quantitativo (análise de agrupamento das variáveis climatológicas mensuráveis) com as de caráter mais qualitativos (identificação dos sistemas atmosféricos e compreensão do ritmo climático no tempo e no espaço).

\section{Resultados Obtidos}

\section{A análise de agrupamento}

O uso da análise de agrupamento possibilitou a identificação de 6 tipos climáticos, distintos e destacados no dendograma (figura 2).

o primeiro grupo é formado pelas unidades de observação meteorológica que se localizam na porção mais ocidental do extremo oeste do Estado de São Paulo. As principais características quantitativas da marcha dos elementos meteorológicos em análise são: valores médios dos totais anuais de chuva variando entre 1230 a $1310 \mathrm{~mm}$, valores médios pluviais em $24 \mathrm{~h}$ de 85,0 mm, verões com valores pluviais médios de $175 \mathrm{~mm}$, primaveras com $120 \mathrm{~mm}$ e invernos com valores de $45 \mathrm{~mm}$ ao ano. Os valores térmicos médios de janeiro variam entre $25,7^{\circ} \mathrm{C}$ a $27,3^{\circ} \mathrm{C}$ e os de julho entre $19,6^{\circ} \mathrm{C}$ a $21,6^{\circ} \mathrm{C}$ (ver figura 4 ).

0 segundo grupo é formado pelas unidades de observação meteorológica localizadas na porção sudoeste da área de pesquisa. As principais características das variáveis climatológicas utilizadas são: valores médios entre 1310 mm (em Naviraí e em Rosana) a 1630 mm (nas unidades de observação inseridas no extremo sudoeste paranaense), com a estação mais chuvosa no verão (com valores entre 155 a $175 \mathrm{~mm}$ ); seguido pelas estações de primavera (120 $\mathrm{mm}$ a $160 \mathrm{~mm}$, sendo que os valores mais expressivos ocorrem na porção sudoeste paranaense e os menos sobre Naviraí), outono (125 mm a $135 \mathrm{~mm}$ ) e a estação de inverno com valores médios entre $120 \mathrm{~mm}$ (em Naviraí e em Rosana) a $160 \mathrm{~mm}$ em Palotina, Cascavel e em Mariluz. Os valores pluviais máximos registrados em 24 horas variam entre 79 a $99 \mathrm{~mm}$ Os valores térmicos de janeiro variam entre $24,1^{\circ} \mathrm{C}$ a $26,1^{\circ} \mathrm{C}$, sendo que os maiores valores são observados em Naviraí. Já os valores térmicos de julho variam de $16,4^{\circ} \mathrm{C}$ a $18,0^{\circ} \mathrm{C}$ (figura 4 ).

O terceiro grupo é formado pelas unidades de observação meteorológica que se encontram nas porções oeste e leste paranaense, a cerca de $23^{\circ}$ de latitude Sul, como mostra a figura 4. As principais características das variáveis climatológicas utilizadas são: totais anuais de precipitação oscilando entre 1230 $\mathrm{mm}$ na porção oeste (às margens do Rio Paraná) a $1630 \mathrm{~mm}$ na porção leste e chuvas registradas em 24 horas com valores médios de 80 a 100 mm. A estação mais chuvosa se configura durante o verão, com valores médios entre $145 \mathrm{~mm}$ (na porção oeste) a $165 \mathrm{~mm}$ (na porção leste), seguida pelas estações de primavera (75 a $85 \mathrm{~mm}$ ), outono (120 a $125 \mathrm{~mm}$ ) e inverno (70 a $85 \mathrm{~mm}$ ). As temperaturas médias de janeiro oscilam entre $24,9^{\circ} \mathrm{C}$ a $28,1^{\circ} \mathrm{C}$ e as de julho em torno dos $18^{\circ} \mathrm{C}$ (figura 4 ).

O quarto grupo é formado pelas unidades de observação meteorológica espaciais de Ivinhema, Apucarana e Rancharia. As principais características 
das variáveis climatológicas utilizadas são: totais anuais de precipitação entre 1230 a $1390 \mathrm{~mm}$, com a estação em que os valores pluviais se apresentam com mais expressividade no verão, com $160 \mathrm{~mm}$ na porção oeste e $190 \mathrm{~mm}$ na leste; seguida pelas estações de primavera com valores médios de $121 \mathrm{~mm}$ a oeste e $140 \mathrm{~mm}$ a leste, outono com valores médios de $95 \mathrm{~mm}$, tanto na porção leste quanto oeste e inverno com valores de $30 \mathrm{~mm}$ a oeste e $70 \mathrm{~mm}$ a leste. Os valores pluviais máximos registrados em 24 horas variam em média de $88 \mathrm{~mm}$. Os valores térmicos médios de janeiro variam de $24,9^{\circ} \mathrm{C}$ a leste e de $28,9^{\circ} \mathrm{C}$ a oeste. Já as médias térmicas para o mês de julho são de $18^{\circ} \mathrm{C}$ tanto a leste quanto a oeste (ver figura 4 ).

O quinto grupo é composto, basicamente, por unidades de observação meteorológica da porção paulista da Raia Divisória. As principais características das variáveis climatológicas utilizadas são: totais anuais médios de precipitação de 1310 mm, com a estação em que apresenta os valores pluviais mais expressivos no verão (175 mm, valores muito próximos ao do grupo I), seguido pelas estações de primavera (110 a $120 \mathrm{~mm}$ ), outono (120 a $125 \mathrm{~mm}$ ) e o inverno com valores médios de $45 \mathrm{~mm}$ ao ano. Os valores pluviais registrados em 24 horas são de 85 milímetros em média. Os valores térmicos médios de janeiro variam entre $25,7^{\circ} \mathrm{C}$ a $27,3^{\circ} \mathrm{C}$. Já os valores médios de julho variam entre $19,6^{\circ} \mathrm{C}$ a $21,6^{\circ} \mathrm{C}$ (ver figura 4 ).

O sexto grupo é o que apresenta características mais complexas na marcha pluvial e térmica da área de pesquisa. Estende-se ao longo de cinco eixos de análise, sendo eles: o eixo Ribas do Rio Pardo - Teodoro Sampaio (ligando a porção noroeste sul-mato-grossense com a região mais central da área de pesquisa), o eixo Teodoro Sampaio - Maringá (configurando como o eixo central da área de pesquisa), o eixo Maringá - Cianorte (originando o eixo que liga a parte central a porção mais ao sul), o eixo Cianorte - Umuarama (formando o eixo que se direciona a porção sudoeste) e o eixo Cianorte - Ivaiporã (o eixo do extremo sul da área de pesquisa). As principais características das variáveis climatológicas utilizadas são: totais anuais médios de precipitação variando entre 1910 a 1310 mm (ao longo do eixo que liga a porção noroeste até a central - Ribas do Rio Pardo a Teodoro Sampaio) e de $1470 \mathrm{~mm}$ médios nos demais eixos de observação. A estação em que apresenta os valores pluviais médios mais expressivos é o verão $(190 \mathrm{~mm})$, seguido pela estação de primavera com valores de $150 \mathrm{~mm}$ a $115 \mathrm{~mm}$ (ao longo do eixo Ribas do Rio Pardo - Teodoro Sampaio), 115 a $145 \mathrm{~mm}$ (ao longo do eixo Teodoro Sampaio - Maringá) e valores médios de 145 a 155 mm entre os eixos Maringá - Cianorte e Cianorte Ivaiporã. No outono, os valores médios são de 135 a $95 \mathrm{~mm}$ (ao longo do eixo Ribas do Rio Pardo - Teodoro Sampaio) e de 95 a 135 mm (ao longo dos eixos Teodoro Sampaio - Maringá, Maringá - Cianorte e Cianorte - Ivaiporã). Já no inverno, os valores decrescem de $70 \mathrm{~mm}$ para $50 \mathrm{~mm}$ (ao longo do eixo Ribas do Rio Pardo - Teodoro Sampaio) e aumento ao longo dos eixos: Teodoro Sampaio - Maringá de $50 \mathrm{~mm}$ para $65 \mathrm{~mm}$, Maringá - Cianorte de $65 \mathrm{~mm}$ para $85 \mathrm{~mm}$ e ao longo do eixo Cianorte - Ivaiporã de $85 \mathrm{~mm}$ para $100 \mathrm{~mm}$. As temperaturas de janeiro da área diminuem de $30,5^{\circ} \mathrm{C}$ para $25,1^{\circ} \mathrm{C}$ ao longo do eixo Ribas $\mathrm{R}$. Pardo - Teodoro Sampaio e $25,1^{\circ} \mathrm{C}$ para $24,1^{\circ} \mathrm{C}$ ao longo dos demais eixos. Já as temperaturas médias de julho variam entre $18,5^{\circ} \mathrm{C}$ a $17,2^{\circ} \mathrm{C}$ de uma forma geral (ver figura 4). 


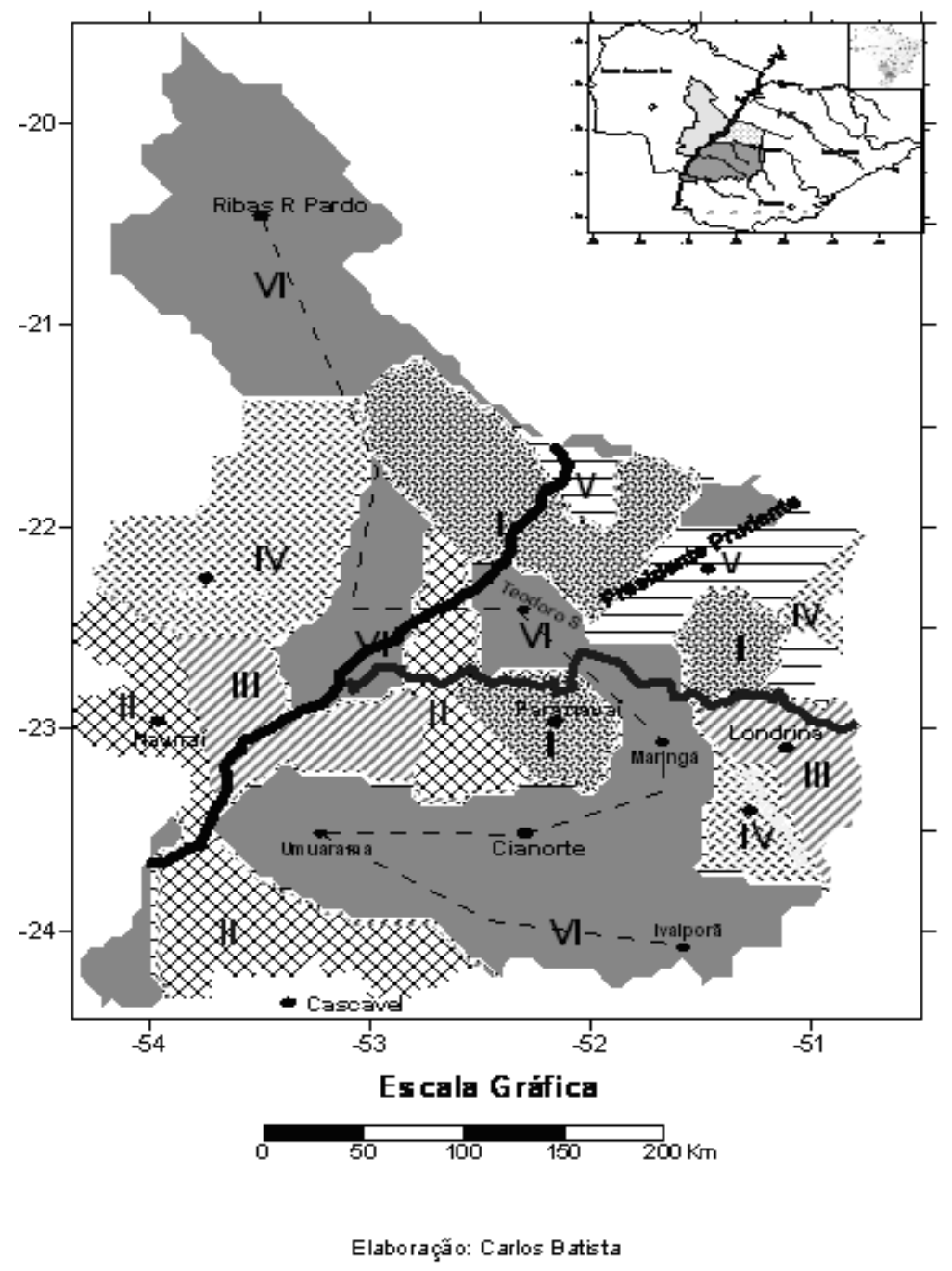

Figura 4. Modelo de tipologias climáticas baseado no agrupamento de variáveis e expressões temporais do clima

\section{A análise genética (a sucessão dos tipos de tempo)}

A análise genética, na maioria dos casos, se configura como uma excelente possibilidade de compreensão do encadeamento dos tipos de tempo atuante e, sobretudo das marchas das variáveis climatológicas temporais e espaciais de um determinado lugar. O emprego da análise genética é uma das principais ferramentas de uso àquelas pesquisas preocupadas em tratar o clima como um fenômeno dinâmico e de ampla interação com o espaço geográfico e seus elementos.

Esta análise foi estabelecida por meio do paradigma do ritmo climático (SORRE, 1951 e MONTEIRO, 1969) e da análise rítmica (MONTEIRO, 1971). 
Apesar da área da Raia Divisória possuir distâncias espaciais relativamente pequenas, suas configurações climáticas se apresentam diante de enorme complexidade, atreladas à própria distribuição dos sistemas atmosféricos, como mostra a figura 5 .

Nessa figura foi possível organizar espacialmente a freqüência dos sistemas atmosféricos com o uso da análise por eixos-transversais, da interpretação do padrão rítmico da área e com o método de Pédélaborde (1959). A partir de então, obteve-se as seguintes configurações dinâmicas da área:

A porção sul-mato-grossense: Essa área encontra-se sob o controle da massa tropical atlântica em cerca de $53 \%$ de todo o ano de 1996 . A massa tropical continental influenciou cerca de $17 \%$ dos dias do ano, com os percentuais mais acentuados durante os meses da primavera. Os sistemas convectivos (CCMs e ITs) tiveram percentuais de $5 \%$ dos sistemas atmosféricos durante 0 ano de 1996, assim como as ZCAS. A freqüência dos sistemas extra-tropicais (PA) corresponderam a $21 \%$ de participação dos sistemas atmosféricos e as frentes frias apenas 1\%. Nota-se ainda que esta porção sul-mato-grossense é influenciada pela massa equatorial continental, sobretudo no extremo noroeste, como também já havia sido destacado por Zavatini (1990) (ver figura 5).

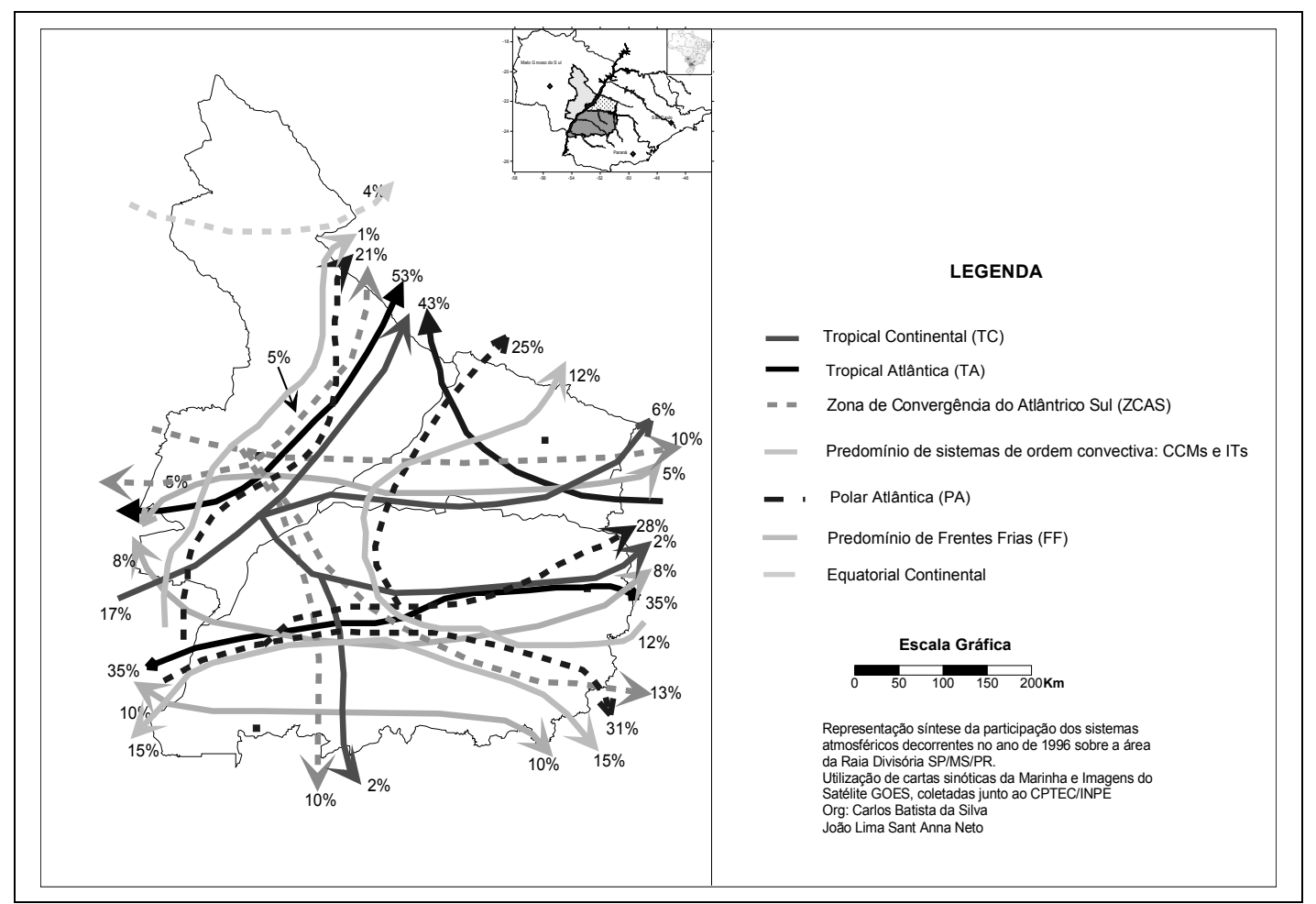

Figura 5. Representação síntese da freqüência espacial dos principais sistemas atmosféricos para "anos-padrão" habitual

A porção paulista: O predomínio nesta porção territorial é o da massa tropical atlântica, com $43 \%$ durante o ano. As ZCAS tiveram uma participação de 
$10 \%$ nesta área. Os sistemas convectivos (CCMs e ITs) tiveram a participação durante todo o ano de 1996 de apenas 5\%. Esta área esteve sob a influência da tropical continental cerca de $6 \%$. Os sistemas frontais, sobretudo as frentes frias e suas repercussões foram responsáveis por cerca de $12 \%$ dos sistemas atmosféricos atuantes. Já a participação dos sistemas extra-tropicais corresponderam a $25 \%$ de todo o ano, como mostra a figura 5 .

A porção paranaense: Esta porção se encontra sob os domínios dos seguintes sistemas atmosféricos: a massa tropical atlântica exerceu influência na área durante $35 \%$ do ano. Já a massa tropical continental $2 \%$ durante o ano. A freqüência percentual das ZCAS para este ano de foi de $10 \%$ ao longo do eixo Londrina-Presidente Prudente e de $13 \%$ entre o eixo Palotina-Cianorte. O extremo Sul desta porção sofreu influência percentual de $10 \%$ dos sistemas convectivos contra $8 \%$ dos mesmos decorrentes entre as latitudes de Cianorte e Londrina. A participação percentual das frentes frias (15\%) foi mais intensa nas latitudes maiores que as de Cianorte, ou seja, todo o quadrante extremo sul da porção. Já em latitudes entre Cianorte-Londrina e em direção a Presidente Prudente os valores percentuais de participação das frentes frias que foram de $12 \%$.

\section{Síntese dos atributos climáticos quantitativos e genéticos}

A realização de um modelo-síntese e a combinação entre o modelo de classificação (de caráter mais quantitativo) realizado por agrupamento (figura 4) e a distribuição genética dos tipos de tempo (figura 5), possibilitou a elaboração de uma carta-síntese da tipologia climática da Raia Divisória.

As razões de se tentar estabelecer a união destes dois atributos (quantitativa e genética) podem ser justificadas pelas necessidades de se representar uma tipologia climática mais complexa, ou seja, que levasse em considerações tantos as variáveis meteorológicas mensuráveis como as de aspectos mais dinâmicos, como é o caso dos sistemas atmosféricos.

Desta forma, foi possível obter 5 grandes unidades climáticas, como destaca a figura 6 .

As principais características destas unidades climáticas podem ser descritas da seguinte forma:

A unidade climática I se localiza na porção sul da Raia Divisória. A mesma surge em uma área fortemente influenciada por sistemas extra-tropicais e frontais. Com os resultados obtidos e representados pela figura 5 observa-se que nessa área os controles exercidos pelos sistemas extra-tropicais e pela atuação das frentes frias são maiores quando comparados às demais regiões. Já a participação dos sistemas inter-tropicais se apresentam de forma mais reduzida. Com o método de classificação de Thornthwaite (1948) foi possível observar que está área é do tipo úmido " $\mathrm{B}_{3}$ " (com níveis de umidade efetiva de cerca de 60) e mesotérmico " $\mathrm{B}_{4}$ "(com índices térmicos de aproximadamente 1000).

A unidade climática II, apesar de se apresentar com os mesmos índices de participação dos sistemas inter-tropicais (TA e TC) da primeira unidade climática, observa-se que as participações dos sistemas frontais e extra-tropicais (PA e PV) são menores do que as decorrentes na unidade climática I. Esta faixa climática apresenta os maiores valores pluviais durante os meses de novembro a 
abril, associados às passagens frontais e à influência de sistemas individualizados. Segundo a classificação climática de Thornthwaite (1948) esta faixa climática apresenta-se como do tipo úmido " $\mathrm{B}_{2}$ " (índice efetivo de umidade em torno de 50) e mesotérmico " $B_{3}$ " (com índices térmicos da ordem de 970).

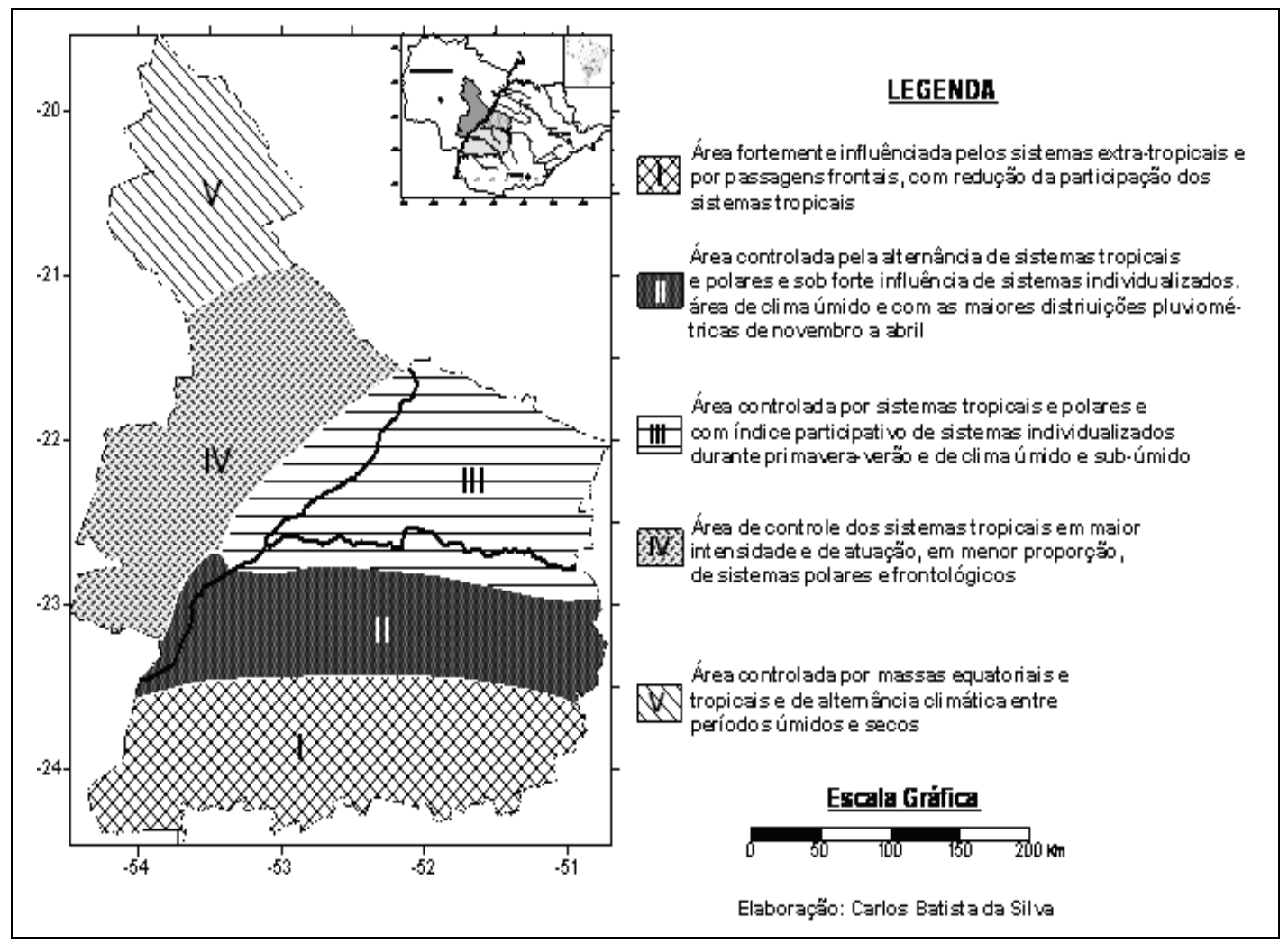

Figura 6. Tentativa de sistematização dos atributos climáticos quantitativos e genéticos na "Raia Divisória"

A unidade climática III é definida pelo confronto direto entre os sistemas inter e extra-tropicais (MONTEIRO, 1971). A mesma é marcada por intensas chuvas que ocorrem de dezembro a fevereiro. O período mais seco é formado pelo trimestre de junho a agosto e as maiores temperaturas não ocorrem nos meses de verão, e sim, durante os meses de setembro e outubro. Esta unidade climática se apresenta sob o domínio da tropical atlântica a maior parte do ano. A freqüência de frentes frias se assemelha às decorrentes na unidade II e com valores de atuação reduzidos dos sistemas extra-tropicais, quando comparado com os decorrentes nas unidades climáticas I e II. Nota-se, ainda, que a área é influenciada o ano todo pela massa tropical continental, com índices mais expressivos durante o mês de novembro e com a maior freqüência de participação de instabilidades tropicais de janeiro a março. Segundo a classificação de Thornthwaite (1948) esta unidade climática pode ser considerada como úmida e sub-úmida (com índice efetivo de umidade de cerca de 10) e do tipo megatérmico (com índices térmicos da ordem de 1180). 
A unidade climática IV é fortemente influenciada tanto pelos sistemas tropicais, quanto pelos sistemas polares. Para Zavatini (1990), esta porção territorial constitui como uma área de climas subtropicais úmidos. Os maiores valores pluviais ocorrem durante os meses de outubro a fevereiro. Essa unidade climática está sob forte influência de sistemas inter-tropicais, sobretudo da tropical atlântica durante todo o ano. A participação dos sistemas frontais e dos sistemas extra-tropicais apresentam índices bem inferiores quando comparados com as demais unidades climáticas, evidenciando a alta influência da continentalidade. Segundo a classificação de Thornthwaite (1948) esta unidade climática pode ser considerada como úmida e sub-úmida (com índice efetivo de umidade com valores aproximadamente de 11) e do tipo megatérmico (com índices térmicos da ordem de 1200).

A unidade climática $V$ apresenta-se sob a atuação direta dos sistemas equatorial continental e tropical. Segundo a definição de Zavatini (1990), a quinta unidade climática, definida neste trabalho, configura-se como de clima tropical alternados por períodos secos e úmidos. A distribuição pluvial nesta área ocorre de outubro a maio, com valores acima dos $170 \mathrm{~mm}$ em cada mês. Adotando a classificação de Thornthwaite (1948) para esta unidade, pôde-se verificar que os índices efetivos de umidade são de aproximadamente 10 e com índices térmicos da ordem de 1280, portanto, segundo a terceira chave de classificação de Thornthwaite, esta unidade climática pode ser considerada como do tipo climático megatérmico.

\section{Considerações finais e conclusões parciais}

Os resultados obtidos por meio da análise quantitativa e a análise dinâmica possibilitaram a compreensão das configurações climáticas da "Raia Divisória". Essa área se apresenta diante do controle de diversos sistemas atmosféricos, configurando não apenas uma maior complexidade climática sobre o local, mas também evidenciando os reais motivos de ser conhecida como de transição climática, como destaca Monteiro (1973) e Zavatini (1983).

A carta síntese da tipologia climática representada na figura 6 mostra que o extremo sul (unidade climática I) da área de pesquisa é controlado por mais tempo por sistemas extra-tropicais quando comparado com as demais regiões em análise. Foram vistas nesta unidade climática, as maiores freqüências participativas dos sistemas frontais e dos de caráter individualizados. Isto, certamente, ajuda a compreender o fato dessa I unidade climática ser tida como uma das mais chuvosas na Raia Divisória.

É essencial destacar que a unidade climática I apresenta características mais uniformes, tanto na distribuição participativa dos sistemas atmosféricos quanto no comportamento das principais variáveis climáticas. Desta forma, possivelmente, a mesma não se enquadre, diretamente, na área que mais sofre com o confronto direto dos sistemas inter e extra-tropicais.

Ainda na porção paranaense, a unidade climática II, revelou-se bastante complexa. Esta área é marcada por apresentar altos valores pluviais durante cinco meses do ano, com início da temporada chuvosa em novembro se 
estendendo até março ou abril. É ainda observado que a freqüência participativa dos sistemas atmosféricos nessa área, ora se assemelha com a Unidade Climática I, na porção sul, ora como a Unidade Climática III da porção paulista. Desta forma, chegamos à conclusão de que, possivelmente, a área de transição climática descrita por Monteiro (1973) - palco dos confrontos diretos entre sistemas inter e extra-tropicais - se inicia nesta segunda unidade climática. Entretanto, este fato merece ser mais bem investigado em uma análise exclusiva da área, centrada suas preocupações em tais desvendamentos.

Uma outra unidade climática que merece ser destacada é o extremo noroeste da área de pesquisa. Esta região, inserida a $21^{\circ}$ de latitude Sul, está localizada numa área controlada por sistemas tropicais e, sobretudo equatoriais, configurando assim uma região de transição e palco de intensas distribuições pluviométricas durante o período de outubro a abril.

Por fim, deve-se ressaltar que muito embora os resultados apresentados na presente pesquisa sejam parciais, portanto, passiveis de serem alterados, o uso da metodologia aplicada nesse ensaio (análise de agrupamento associada a análise genética) se mostrou como sendo uma ótima ferramenta de análise para estudos que visam a classificação climática.

\section{Referências bibliográficas}

ABLER, R, ADANS, J \& GOULD, P. Classification. In:. Spacial organization the geographer's view of the world. Englewood Cliffs, New Jersey, 1971.

AMORIM, M.C.C.T. Ilhas de calor em Birigui/SP. Revista Brasileira de Climatologia. Presidente Prudente. Ano 1. p 121-130. 2005.

AUOAD, M. S. Tentativa de classificação climática para o Estado da Bahia: uma análise quantitativa dos atributos locais associados à análise qualitativa do processo genético. Rio de Janeiro. IBGE. 1982.

AYOADE, J.O. On the use of multivariate technique in climatic classification and regionalization. Arch. Geoph. 197

BERGERON, T. Richtlinien einer dynamischen klimatologie. Met. Z.. Braunschweig: 47:246-62. 1939.

BJERKNESS, J. On the dynamics of the circular vortex with application to the atmosphere and atmospherie vortex and wave motions. Geof. Publ. Oslo 1921.

BOIN, M.N. Chuvas e erosões no Oeste Paulista: uma análise climatológica aplicada. 2000. Tese (Doutorado em Geografia) IGCE de Rio Claro, Rio Claro.

CONTI, J. B. Circulação secundária e efeito orográfico na gênese das chuvas na região lesnordeste paulista. São Paulo. (Série teses e monografias) USP/IG, 1975. HANN, J. Handbook of climatology. New York. 1903.

IBGE - Inst. Bras. de Geografia e Estatística. Mapa pedológico do Brasil (IBGE, 2005). JOHNSTON, R.J. - Choice in classification: the subjectivity of objectivity methods. Annals of Assoc. Am. Geographers. Washington, 58 (3), 1968.

KOEPPEN, W. Climatología. México. Fondo de Cultura e Economia. 1923

MC BOYLE, G.R. Climatic classification of Australian by computer. Climate in Review. Boston, 1973.

MONTEIRO, C.A de F. Notas para o estudo do clima do Centro-Oeste Brasileiro. Revis-

ta Brasileira de Geografia. Ano XIII Jan-Mar de 1951 
Da necessidade de um caráter genético à classificação climática. In Revista Geográfica. XXXI (57):29-44. Rio de Janeiro (IPGH), 1962.

. A frente polar atlântica e as chuvas de inverno na fachada sul-oriental do Brasil: contribuição metodológica à análise rítmica dos tipos de tempo no Brasil. São Paulo (Serie tese e monografia), 1969.

IGEOG/USP, 1971. Análise Rítmica em Climatologia. Climatologia, 1 São Paulo .

A dinâmica climática e as chuvas no estado de São Paulo. São Paulo. IGEOG/USP, 1973.

MILLER, A. A. Climatology. London: Methuen, 1931.

MORIZE, H. Contribuição aos estudos do clima no Brasil. Rio de Janeiro. Ministério da Agricultura, Indústria e Comércio. 1927.

PASSOS, M.M Dinâmicas socioambientais, desenvolvimento local e sustentabilidade na Raia Divisória SP/PR/MS. Presidente Prudente/Maringá (projeto de pesquisa) FAPESP, 2006.

PEDELABORDE, P. Introduction a l'étude scientifique du climat. Centre de Documentation. Universitaire. Paris. 1959

ROSSBY, C.G. Fluid mechanics applied to the study of atmospheric circulation.

A study of flow patterns with the aid of isentropic analysis. Chicago. Man Inst. Technolg. $125 \mathrm{pp} 1938$.

SANT'ANNA NETO, J.L. Ritmo climático e a gênese das chuvas na zona costeira paulista. 1990. Dissertação (Mestrado em Geografia). Faculdade de Filosofia, Letras e Ciências Humanas, Universidade de São Paulo, São Paulo.

As chuvas no Estado de São Paulo: contribuição ao estudo da variabilidade e tendências da pluviosidade na perspectiva da análise geográfica. 1995. Tese (Doutorado em Geografia). Faculdade de Filosofia, Letras e Ciências Humanas, Universidade de São Paulo, São Paulo.

História da Climatologia no Brasil: gênese e paradigmas do clima como fenômeno geográfico. 2001. Tese (Livre-Docência). FCT/UNESP, Presidente Prudente/SP

SERRA, A \& RATISBONNA, L. As massas de ar da América do Sul. Rio de Janeiro. Ministério da Agricultura (Serviço de Meteorologia). 1942.

SORRE, M. Les fundaments de la geographie humaine. Paris. Librarie Armand Colin, 1951

TARIFA, J.R. Fluxos Polares e as Chuvas de primavera - verão no Estado de São Paulo. São Paulo (Série Teses e Monografias). IGEOG/USP. São Paulo, 1975.

TARIFA, J.R, SETTE, D.M, MADRUGA, L.C, MOREIRA, M.L.C, ORMOND, G.L, DIAS FILHO, V \& SANTOS, J.F Atlas Climatológico de Mato Grosso. SEPLAN, Laboratório de Climatologia da Universidade Federal de Mato Grosso, 2006.

THORNTHWAITE, C.W. Na approch towards a rational classification os climate. Geog. Rev. 38:55-94. 1948

TOLEDO, G.S. Tipos de tempo e categorias climáticas na Bacia do Alto Tietê: ensaio metodológico. 1973. Tese (Doutorado em Geografia). Faculdade de Filosofia, Letras e Ciências Humanas, Univ. de São Paulo, São Paulo.

ZAVATINI, J. A. Variações do ritmo pluvial no oeste de São Paulo e norte de Paraná: eixo Londrina, Presidente Prudente e Araçatuba. 1983. Dissertação (Mestrado em Geografia) FFLCH/USP, São Paulo.

A dinâmica atmosférica e as chuvas no Mato Grosso do Sul. 1990. Tese (Doutorado em Geografia). Faculdade de Filosofia, Letras e Ciências Humanas da Universidade de São Paulo, São Paulo. . Estudos do Clima no Brasil. São Paulo, 2000. 